\title{
Sleep-Disordered Breathing in Neurological Diseases
}

\author{
Rafał Rola \\ Institute of Psychiatry and Neurology \\ Poland
}

\section{Introduction}

Episodes of hypoxia and hypercapnia occurring during apneas significantly dilate blood vessels in the brain (both hypercapnia and hypoxia are potent stimuli of cerebral blood vessels dilation - Guyton, 2005). This results, together with a concomitant increase of mean arterial pressure, in average blood flow increase in the cerebral vessels. Studies in healthy volunteers (Przybylowski, 2003) have shown that episodes of breath apneas cause an increase of cerebral blood flow compared with resting conditions (43\% on average). Following an episode of apnea, hyperventilation (with normoxia and hypocapnia) significantly decreases flow in the middle cerebral artery as compared to quiet breathing by $20 \%$ (Przybylowski, 2003). In normal subjects sleep reduces the vasodilatation response to a hypoxia (Meadows, 2004). A number of different mechanisms triggered during sleep apneas can influence the blood flow in the brain. The increase in intracranial pressure, together with a negative pressure in the chest, may reduce the perfusion of the brain (Jennum, 1989). More frequent significant carotid artery stenosis (Silvestrini et al, 2002; Nachtmann et al, 2003) and flow disturbances in the intracranial arteries (Behrens et al, 2002; Nachtmann et al, 2003) were found in patients with sleep-disordered breathing as compared with a population of healthy controls. There was also found that: cerebrovascular autoregulation reserve and hypercapnia triggering cerebral blood vessels dilatation are reduced in patients with obstructive sleep apneas as compared with the control group (Balfors, 1994). Similarly, studies of cerebral blood flow autoregulation in patients with sleep disordered breathing show impaired and delayed expansion of cerebral blood vessels in response to hypoxia (Urbano, 2008). Short-term mechanisms, associated with airway obstruction and hypoxia during sleep, are of paramount importance in the pathophysiology of cerebral circulation disorders and ischemic stroke. During obstructive apnea there is a temporary increase in blood flow through the brain vessels due to hypoxia and hypercapnia, but this increase is smaller than that of healthy people. Hyperventilation which follows the apnea causes hypocapnia and normoxia with significant reduction of blood flow through the brain vessels. Obstructive sleep apnea promotes a substantial fall in cerebral blood flow (Culebras et al, 2004; Netzer et al, 1998). It seems that short-term mechanisms, associated with apnea during sleep, underlie the observed periodicity of brain ischemic stroke occurrence during the day and more frequent prevalence of ischemic stroke in the early morning hours (Mohsenin, 2003; Yaggi, 2003). 
The patomechanisms described above, triggered during obstructive apneas in sleep, foster the development of several cardiovascular diseases, including stroke. One should be aware of highly complex mechanism of formation and interaction between apneas and coexisting metabolic pathological disturbances such as obesity, impaired glucose and lipid metabolism and impaired endothelial functions in cerebrovascular disorders. These patomechanisms often triggered or aggravated by apnea initiate a vicious cycle of pathological metabolic disorders, vascular and structural, that start or grow an existing cerebrovascular pathology.

\section{Sleep-disordered breathing (SDB) in patients with ischemic stroke}

\subsection{Sleep-disordered breathing (SDB) as a risk factor for ischemic stroke}

The first controlled study of sleep related breathing disorders in cerebrovascular diseases were carried out in the 80s. They concerned the snoring as a risk factor for ischemic stroke. The first studies were published by a group of Palomaki (Partinen et al, 1985). They compared the incidence of snoring in 50 men with ischemic stroke with a control group. The study was retrospective with use of a standardized questionnaire. Patients were divided into groups of regularly snoring (every night), often and seldom. Polysomnographic studies were not performed. It was shown that the relative risk of ischemic stroke is 10.8 times higher in regular snorers as compared with not snoring patients. Further results of these investigators have shown that snoring is independent of other risk factor for ischemic stroke (Palomaki 1989, 1991). Results of other studies on snoring as a risk factor of ischemic stroke, show an increased relative risk of stroke in snoring people (Koskenvuo, 1987). The largest cohort study of over 70 thousands women (Nurses Health Study), showed an increased risk of ischemic stroke in regularly snoring women (risk ratio - RR 1.88) and irregularly snoring women (RR 1.60) (Hu, 2000). It should be emphasized that the cited studies were done with the use of different questionnaires. Both the design of different survey questions, the lack of clear criteria for classification of patients as regularly, often and rarely snorers in different studies, and the self- assessment of patients (some snoring patients are not aware of it) can cause false results. The interpretation of these results should be cautious (Harbison, 2000). More recent studies (Davies, 2003) did not show an increased risk of ischemic stroke among snoring men but excessive daytime sleepiness which is associated with an increased risk of ischemic stroke with a relative $R R=3.07$ (Davies, 2003).

In recent years a well-designed studies, with large number of participants, were published on the impact of snoring in other vascular diseases. It has been found, that snoring has negative effect on the incidence, clinical course and mortality of myocardial infarction (Janszky, 2008). In women with type II diabetes snoring increases the risk of hyperlipidemia and increases levels of triglycerides (Williams, 2007). Snoring also increases the risk of diabetes (Al-Delaimy, 2002). Snoring, regardless of other risk factors, increases the incidence of carotid atherosclerosis (Lee, 2008). Recent studies (Davies, 2003), however, do not prove that snoring is a direct risk factor for ischemic stroke. A series of new reports indicate the importance of snoring in the development of risk factors for cerebrovascular diseases (Williams, 2007; Lee, 2008). Snoring, especially loud and habitual, can indirectly contribute to the development of ischemic stroke.

The first studies concerning the sleep-disordered breathing in patients with ischemic stroke, with a quantitative assessment of respiratory dysfunction, were conducted in the 90s. It was shown that among 47 patients with ischemic stroke $72 \%$ have breathing problems during sleep (defined as AHI> 10), $53 \%$ of patients in this group have had AHI> 30, and 30\% 
of patients have had AHI > 40 (Good 1996). Mohsenin and Valor (1995) showed that, among patients with ischemic stroke SDB (AHI> 10) occur in $80 \%$ of patients. Another studies (Bassetti, 1996, 1997, 1999), conducted on 128 patients with ischemic stroke and 28 in the control group, showed the incidence of SDB (AHI> 10) in $62 \%$ of patients with ischemic stroke, compared with $12,5 \%$ in the control group. It has been also shown that the incidence of apneas is similar and significantly higher in patients with ischemic stroke and TIA than in the control group (Bassetti, 1996). These results suggest that sleep-disordered breathing is a risk factor for ischemic stroke, rather than its consequence.

Similar results for sleep-disordered breathing in patients with ischemic stroke and TIA were obtained in the group of 161 patients (Parra, 2000). The incidence of sleep-disordered breathing in the group with ischemic stroke was $74.5 \%$, while in the TIA group, $61.5 \%$. Another study (Wessendorf, 2001) have shown the incidence of apnea during sleep in $44 \%$ of patients with ischemic stroke, obstructive apneas were the most prominent type of SDB $94 \%$, central apneas occurred in $6 \%$ of patients. Turkington (2002) observed presence of SDB (AHI> 10) in $61 \%$ of patients with ischemic stroke. In other studies (Harbison, 2002), the incidence of sleep-disordered breathing in patients with acute stroke was $94 \%$ and decreased during hospitalization to $72 \%$ within 6 weeks after stroke. Results presented by Iranzo (2002) show that SDB (AHI> 10) in the first night after the stroke occurred in $62 \%$ of patients. Another study (Kaneko, 2003) showed sleep-disordered breathing in $72 \%$ of patients with ischemic stroke. A prospective study of 120 patients with excessive day sleepiness have shown the relationship between the severity of obstructive apneas and hypopneas in patients in the first day of stroke and the clinical course and functional capacities, measured using the Barthel scale (Turkington, 2002). Obstructive apneas and hypopneas were also associated with increased probability of death and disability after stroke (Turkington, 2004). Another study assessed the occurrence of sleep-disordered breathing in 139 patients with ischemic stroke within the first three days of stroke, comparing characteristics of the strokes that occur at night and during the day. It was found that strokes occurring at night were associated with higher risk of SDB prevalence $(\mathrm{RR}=2.62)$ compared with strokes occurring during the day. The authors suggest pathophysiological association between apneas during sleep and nocturnal strokes (Martinez-Garcia, 2004). Another studies evaluated the relationship between arterial blood pressure values after stroke and sleep-disordered breathing and prognosis after stroke. It was found that sleep-disordered breathing is associated with elevated nocturnal arterial blood pressure and the lack of nocturnal arterial blood pressure decrease (non dippers). There was little correlation between the severity of neurological symptoms, clinical course (degree of disability assessed with Barthel scale) and the severity of apnea (Selic, 2005). A much larger relationship occurred between nocturnal blood pressure abnormalities and the severity of the clinical course of stroke (Selic, 2005). The lack of nocturnal arterial blood pressure decrease (non dippers), however, is associated with sleep-disordered breathing and increased activity of sympathetic nervous system. Prospective study of 102 patients with ischemic stroke and sleep-disordered breathing showed significantly higher risk of ischemic stroke in patients with AHI> $10(\mathrm{RR}=3.5)$, regardless of other risk factors (Dziewas, 2005). Prospective, cohort study ( follow-up of 3.4 years ; 1022 patients diagnosed with obstructive apneas and hypopneas - $68 \%$ of the total population), showed a significantly higher risk of stroke or death $(R R=1.97, p=0.01)$ in patients with sleepdisordered breathing (AHI> 5) compared with the control group regardless of other risk 
factors (age, sex, BMI, arterial hypertension, atrial fibrillation and lipid disorders) (Yaggi, 2005). Correlation studies show a trend related to the higher risk of ischemic stroke and death in patients with more advanced sleep-disordered breathing (Yaggi, 2005). Patients with $\mathrm{AHI}<35$ and $\mathrm{AHI}>35$ had a relative risk ratios respectively 1.74 and 3.3. Another prospective study of stroke risk in patients with sleep-disordered breathing based on a cohort of Wisconsin (Wisconsin Sleep Cohort Study, 1121 patients without SDB and 1475 patients with SDB (AHI> $5)$, showed significantly higher incidence of ischemic stroke in patients with advanced apneas (AHI> 20) compared with control group matched demographically and by other risk factors, (Arzt, 2005). The relative risk of ischemic stroke in patients with AHI> 20 in a four-year followup was RR $=4.33$ (Arzt, 2005). Most studies conducted so far focused mainly on obstructive sleep-breathing disorders in stroke. Most of the observational studies of patients with ischemic stroke indicate a small proportion of the central type apneas (20\%) (Bassetti, 1996; Parra, 2000; Yaggi, 2003; Kaneko, 2003; Selice, 2005). Respiratory disturbances of the central type (Cheyne-Stokes breathing pattern) are observed mainly in patients with ischemic stroke with concomitant heart failure (Nopmaneejumruslers, 2005). Another prospective study of elderly people (394 pts aged 70 to 100 years) during 6 year follow-up showed significantly higher incidence of ischemic stroke in patients with severe obstructive apneas and hypopneas (AHI> 30) with a relative risk ratio RR: 2.52 (Munoz, 2006). Further prospective studies assessing the mortality of patients with stroke and sleep-disordered breathing in 10-year follow-up showed a significantly higher risk of death in patients with obstructive apneas and hypopneas $\mathrm{RR}=1.76$, compared with the control group. Mortality of patients with central sleep apneas was comparable with the control group (Sahlin, 2008). Patients with ischemic heart disease and SDB (AHI> 5) were at increased risk of ischemic stroke RR $=2.69$ in tenyears perspective (Valham, 2008). Accordingly, with increasing severity of sleep- disordered breathing ( $\mathrm{AHI}<15$ and $\mathrm{AHI}>15)$, the risk of stroke was higher $(\mathrm{RR}=2.44$ and $\mathrm{RR}=3.56)$.

\subsection{Sleep-disordered breathing in patients in the acute phase of ischemic stroke}

Sleep-disordered breathing occurs in 30 to $90 \%$ of patients in the acute phase of ischemic stroke. SDB can be divided into two types - central apneas and obstructive hypopneas and apneas. In the acute phase of ischemic stroke obstructive apneas are predominant - (Parra, 2000; Yaggi, 2003; Kaneko, 2003). Central-type apneas occurring in the acute phase of ischemic stroke are promoted by impaired consciousness, brain edema and location of ischemic lesions in the medulla. Supine position and dysphagia favor obstructive type apneas. Recently, many research groups have sought to determine the relationship between the occurrence, type and severity of apnea in the acute phase of ischemic stroke and its outcome. It was found that a quantity of central apneas since the onset of disease decreases over time (Parra, 2000; Kaneko, 2003) while obstructive apneas remain constant in patients with ischemic stroke (Parra, 2000; Kaneko, 2003; Harbison, 2002). The next stage of the research was to determine the relationship between the number of obstructive type apneas during sleep and clinical improvement in patients with ischemic stroke. It was found that the severity of SDB in the acute phase of ischemic stroke negatively correlates with the clinical improvement of neurological syndrome (Turkington, 2004; Harbison, 2002; Kaneko, 2003). The increased number of obstructive type apneas in the acute phase of ischemic stroke is highly correlated with increased mortality in patients with ischemic stroke, especially if the apneas last longer than 30 seconds (Turkington, 2004). The severity of apneas in the acute phase of ischemic stroke may be regarded as a predictor of poor neurological improvement in patients with 
similar severity of neurological symptoms on admission (Cherkassky, 2003) and duration of hospitalization (Kaneko, 2003). Improvement of the functional status of patients (assessed with the Barthel scale) after stroke is negatively correlated with the frequency of incidents of sleepdisordered breathing (Turkington, 2004; Kaneko, 2003).

\subsection{Treatment of sleep-disordered breathing in patients with ischemic stroke}

Treatment of sleep-disordered breathing in patients with ischemic stroke is strongly dependent on the patient's clinical condition (Hui, 2002). It was shown that among patients with profound neurological deficit CPAP treatment results are unsatisfactory and do not bring the improvement of respiratory parameters (Sandberg, 2001; Wessendorf, 2001). These failures are mainly due to poor tolerance of CPAP and poor compliance among patients with stroke (Sandberg, 2001; Wessendorf, 2001; Hui, 2002). Results published in 2005 regarding the introduction of CPAP treatment in patients with first episode of ischemic stroke and severe obstructive sleep apneas (AHI> 20) showed a significantly lower occurrence of subsequent vascular events (cerebral and cardiac) in patients treated with CPAP - $6,7 \%$ compared with $36 \%$ in patients not treated within two months of follow-up (Martinez-Garcia, 2005). Other authors did not observe statistically significant benefit from the introduction of CPAP treatment in stroke patients with severe obstructive sleep apneas (AHI> 30) (Hsu, 2006). Further prospective study on 449 patients with mild and severe OSAS and CPAP treatment, showed significantly lower risk of cardiovascular event, including stroke (Buchner, 2007). Therapy of patients with severe obstructive sleep apneas and arterial hypertension is postulated as a primary prophylaxis of ischemic stroke (Goldstein, 2006). Recent prospective study in 223 in stroke patients with concomitant obstructive sleep apneas treated with CPAP have reported that treated patients have reduced risk of death compared with not treated in 5-years follow-up (Martinez-Garcia, 2009). It should be noted that the failure of CPAP treatment is usually the result of a difficult cooperation and intolerance of treatment in patients after ischemic stroke. Although there are discrepant reports in the literature, the method of CPAP treatment appears to be effective in preventing further stroke incidents and reduces the risk of death if there is good tolerance of this type of treatment. These results should not limit the interest of researchers in the problem of obstructive sleep apnea in stroke patients. There are several recognized methods of prevention and treatment of sleep-disordered breathing, which can be used successfully in patients with a history of ischemic stroke. These methods include weight reduction, improving sleep hygiene - proper sleep position, avoiding the supine position, avoiding use of alcohol before bedtime, and very important issue - limitation of the use of sleeping pills, particularly the group of benzodiazepines, which may lead to depression of central respiratory center and worsen SDB. Surgical treatment has a prominent place in the treatment of SDB. Correction of the anatomical defects of nasopharynx results in many patients in reduction of the number and severity of obstructive sleep apneas. It is important among stroke patients to select a group with sleep-disordered breathing because of a double benefit - diagnostic and therapeutic, as it allows to modify on of the risk factor-SDB in these patients.

\section{Sleep-disordered breathing disorders in neurological diseases}

Respiratory disorders in patients with neurological diseases may be a result of damage to different parts of the respiratory rhythm generator and controlling structures responsible for 
generation of respiratory movements (neuromuscular disorders). Vascular damage to the respiratory center may lead to central respiratory disturbances. Neurodegenerative disease can damage the respiratory center (Cormican, 2004), as well as demyelinating lesions (Auer, 1996) located within the respiratory center. Damage of the axons projecting from respiratory center to spinal cord a-motoneurons (cervical spine trauma, demyelinating plaques in multiple sclerosis) can cause respiratory disorders. Damage to the a-motor neurons of the spinal cord (amyotrophic lateral sclerosis, post-polio syndrome) leads to respiratory failure (Aboussouan, 2005). Similarly, peripheral nerve conduction abnormalities (Guillian-Barre syndrome and congenital polyneuropathy) may lead to hypoventilation and respiratory failure. Disorders of the neuromuscular transmission (myasthenia gravis, botulinum toxin poisoning) and primary muscle disorders (myopathies, muscular dystrophy) can cause respiratory disorders. Physiological sleep, especially REM sleep phase, is a period vulnerable to the occurrence of respiratory disorders. Often the first sign of respiratory failure in the course of neurological diseases is sleep-disordered breathing (Katz, 2009; Landon, 2006). Due to the risk of significant respiratory complications, often fatal, in the course of certain neurological diseases (amyotrophic lateral sclerosis, glycogenosis type II), it is advisable to closely monitor the sleep-disordered breathing among such patients (Bach, 2004; Birnbaum, 2009). Early detection of sleep-disordered breathing, thanks to the possibilities of non-invasive respiratory therapy in the earlier stages of the disease, can significantly improve the quality of life of patients and their prognosis (Bourke, 2003; Farrero, 2005; Mustfa, 2006; Bourke, 2006; Katz, 2009; Ambrosino, 2009). An interesting fact is the presence and influence of breathing disorders in neurological diseases not associated in their pathophysiology with respiratory problems. Examples of such diseases include Alzheimer's disease, Parkinson's disease and epilepsy. Sleep-disordered breathing can often worsen the course of these diseases. The main group of neurological disorders often associated with respiratory disorders are neuromuscular diseases.

\subsection{SDB in neuromuscular diseases}

Sleep-disordered breathing and respiratory failure are a common consequence of neuromuscular diseases. Respiratory failure as a result of the underlying disease is more prominent during physiological sleep. Ventilation disorders caused by weakening of breathing muscles occur mostly in patients at REM sleep stage. Physiological relaxation of most of the body muscles (except diaphragm and oculomotory muscles, Tabachnik, 1981) and respiratory drive instability may be the cause of breathing disorders during this phase of sleep. It was confirmed in patients with neuromuscular diseases in which blood saturation was measured (Bourke, 2002; Katz, 2009). Sleep-disordered breathing in patients with neuromuscular diseases can be either of central or obstructive origin. The most common type of sleep-disordered breathing in these patients are central hypoventilation and central apneas.

\subsubsection{Motor neuron disease}

Motor neuron disease leads to progressive muscle weakness, including respiratory muscles. This results in decreased breathing exertion and hypoventilation (Lyall, 2001). The course and severity of respiratory distress affects the clinical course of disease. First of all, bulbar form of amyotrophic lateral sclerosis is associated with more rapid development of respiratory failure (Hadjikoutis, 2001). Respiratory failure develops in a significant majority 
of patients with motor neuron disease and is a major cause of mortality. Studies concerning sleep disorders and sleep-disordered breathing in motor neuron disease often differ significantly. Some studies indicate a significantly higher incidence of sleep-disordered breathing in the early stages of the disease (Santos, 2003) and fragmentation of sleep (Arnulf, 2000) with the absence or substantial reduction of the duration of REM sleep and increased number of arousals (Takekawa, 2001). Sleep-disordered breathing was mainly of central origin (Santos, 2003; Bourke, 2002). The severity of respiratory distress tended to decrease with time of disease; in patients with disease lasting less than 1 year $\mathrm{AHI}=23$, while in patients suffering from more than 2 years $\mathrm{AHI}=16$. Other studies in the early stages of the disease (Kimura, 1999; Ferguson, 1996, David, 1997) do not show significantly higher incidence of SDB. Some authors have postulated the relationship between the number of apneas during sleep and the clinical course (bulbar form) (Santos, 2003; Kimura, 1999), others did not observed similar corelations (Ferguson, 1996). The incidence of SDB in the early stages of motor neuron disease is estimated from 16 to $76.5 \%$ (Bourke, 2002). The reasons for such divergent results are due to small study groups of patients (usually not exceeding 20 persons), a different methodological approach (polysomnography vs. portable devices) and a different stage of the disease and its clinical course. Summarizing the results of these studies it is clear that sleep-disordered breathing in patients with motor neuron disease in the early stages of the disease are mostly represented in the form of shallow breaths of central origin, arising from the failure of the diaphragm muscle contraction. Obstructive disorders are rare and are associated rather with the bulbar form (Bourke, 2002). With disease progression the severity of respiratory distress during the day and during sleep increases. Most researchers (Kimura, 1999; Bourke, 2002; Bourke, 2003; Santos, 2003; Mustfa, 2006; Ozsancak, 2008; Ambrosino, 2009) suggest that early detection of major breathing problems during sleep is important and early qualification for home treatment of patients with non-invasive ventilation methods should be performed (Bourke, 2003; Santos, 2003; Mustfa, 2006; Ozsancak, 2008; Ambrosino, 2009). Along with the improvement of technical devices and their increased availability, treatment should be introduced as soon as possible (Ozsancak, 2008; Ambrosino, 2009). A number of studies in patients with motor neuron disease proved a beneficial effect of using non-invasive ventilation during sleep on the quality of life and prognosis (Bourke, 2003, 2006; Moustfa, 2006). Randomized study of 41 patients with motor neuron disease using non-invasive ventilation during sleep (Bourke, 2006) showed a significant increase in their quality of life and its prolongation, for an average 205 days compared with the control group. The greatest benefit was found in the group of patients with less severe involvement of bulbar muscles (Bourke, 2006). Due to the nature of SDB in patients with motor neuron disease (mainly central hypoventilation), the optimal screening study evaluating the severity of respiratory distress seems to be, both in terms of accessibility and sensitivity, overnight oximetry.

\subsubsection{Duchenne muscular dystrophy}

Sleep-disordered breathing in patients with Duchenne muscular dystrophy has a characteristic clinical course (Barbe, 1994). In children under 10 years mostly obstructive apneas occur, while in older children, with the development of disease, the apneas of central origin predominate (Smith, 1989; Suresh, 2005). The occurrence of obstructive sleep apnea and snoring at a younger age is associated with frequent enlargement of the tongue (Barbe, 1994; Suresh, 2005) 
and a relatively good function of the respiratory muscles. With age, symptoms of respiratory muscle failure develop and lead to sleep- apneas of central type. The study of 34 patients aged from 1 to 15 years showed the presence of daily symptoms of sleep-disordered breathing in $64 \%$. Polysomnographic studies have shown obstructive SDB incidence in 31\% (median age 8 years ) and central type SDB in 32\% (median age 13 years) (Suresh, 2005). The non-invasive ventilation therapy during sleep significantly reduced the number of episodes of breathing problems, an average of 11 per hour in 5 years. The authors recommend polysomnography study in patients under 10 years of age with symptoms of sleep-disordered breathing. In children above 10 years of age, with early signs of respiratory distress, polysomnographic studies must be performed. Treatment with non-invasive home night ventilation should begin as early as possible (Suresh, 2005; Katz, 2009). In children with Duchenne muscular dystrophy the best predictor of outcome is the vital capacity, respiratory parameters during sleep are of less importance. Recommendations of the American Thoracic Society (2006) include: a history of breathing problems during sleep during each visit, regardless of age, in the case of a patient immobilized in a wheelchair polysomnographic evaluation once a year. When polysomnography is not feasible it is recommended to control overnight pulse oximetry (Kirk, 2000) and evaluate arterial gasometry during follow-up visits.

There are no large systematic studies on sleep -disordered breathing in other types of muscular dystrophies. Recently published study analyses SDB in 51 patients with facioscapulohumeral muscular dystrophy (Della Marca, 2009). 22 patients had abnormal breathing during sleep, 13 of them had obstructive breathing disorders ( 3 of them required the CPAP treatment). In 4 patients during REM sleep hypoxia of central origin were found, 3 patients had mixed type of respiratory disorders. Other parameters such as BMI, daytime sleepiness, and neck circumference did not correlate with the occurrence of sleep-disordered breathing.

\subsubsection{Myotonic dystrophy}

Myotonic dystrophy (DM) is the most common neuromuscular disease in the adult population (Rowland, 2005). During sleep, individuals with DM may develop hypopneas and apneas, obstructive, central and mixed (Finnimore, 1994; Kiyan, 2009). These disorders occur in about half of patients with DM (Labanowski, 1996; Kiyan, 2009). Polysomnographic studies show a reduction in the duration and sleep efficiency, increased number of nocturnal arousals and time of light sleep (NREM1) and decrease in the time of REM sleep (Bourke, 2002). During the day, the rhythm of breathing in patients with myotonic dystrophy is irregular while awake, as well as during light sleep. The main problems are observed in the REM phase of sleep (Finnimore, 1994). Usually, symptoms of sleepdisordered breathing in patients with myotonic dystrophy are far before of signs of respiratory distress during the day (Bourke, 2002). Daytime sleepiness in patients with DM (assessed with the Epworth sleepiness scale $\geq 10$ ) is felt by about $50 \%$ of patients (Laberge, 2009). Objective tests of daytime sleepiness (MSLT test) show excessive daytime sleepiness in $69 \%$ of the respondents (Laberge, 2009). Excessive sleepiness correlates with the degeneration of serotonergic neurons in the raphe nuclei and central superior nucleus of the reticular formation (Ono, 1998). Authors describe the decrease of orexin concentration in the cerebrospinal fluid, which indicates a similarity in the pathomechanism of sleepiness in narcolepsy and DM (Martinez-Rodriguez, 2003). Due to the progressive nature of the disease and mixed character of breathing disorders, respiratory treatment should be 
implemented only in specialized centers. Sometimes it is necessary to apply a positive pressure with a variable values (BiPAP, Auto-CPAP) or additional oxygen therapy. In the treatment of excessive sleepiness psychostimulants - metylfenidad and modafinil are used.

\subsubsection{Myasthenia}

Disorders of neuromuscular transmission in the course of myasthenia gravis may cause sleep-disordered breathing of central type, especially during REM sleep accompanied by declines in blood oxygen saturation (Quera-Salva, 1992; Manni, 1995). The nature of respiratory disorders is similar as in other neuromuscular diseases. The severity of respiratory distress is associated with disease severity. Sleep-disordered breathing in patients with myasthenia gravis is particularly pronounced before the occurrence of myasthenic crisis and precede symptoms of respiratory failure due to exhaustion of the respiratory muscles during the night. At that time hypercapnia is the most characteristic symptom. Hypoxia and hypercapnia occurring during sleep are often the case of morning headaches and progressive fatigue associated with underlying disease. Implementation of treatment reduces sleep-disordered breathing (Amino, 1998). There is no clear data to evaluate the incidence of SDB in patients with well-controlled myasthenia gravis. Some authors have shown an increased incidence of obstructive type of sleep-disordered breathing in patients with myasthenia gravis (36\% compared to $15-20 \%$ expected in the population (Nicolle, 2006). Other authors (Prudlo, 2007) found no correlation between the occurrence of myasthenia gravis and the occurrence of obstructive breathing disorder during sleep. Most studies on the prevalence of SDB in myasthenia gravis was conducted on small groups (up to 30 patients). These results should therefore be carefully analyzed. Currently it seems that the periods of worsening of the disease are associated with increased risk of respiratory distress, while the periods of remission during medical treatment are not associated with an increased risk of respiratory disorders during sleep (Prudlo, 2007).

\subsubsection{Glycogenosis type II-Pompe disease}

Pompe disease is a chronic, progressive metabolic myopathy associated with deficiency or reduced activity of the acid alpha-glucosidase enzyme. As a result, glycogen storage occurs in tissues and impairs their functioning. Depending on the degree of enzyme defficiency clinical course of disease may be different. The infantile form is associated with a complete lack of the enzyme. Symptoms begin within the first few months of life. The usual presenting features are cardiomyopathy and hepatomegaly leading to progressive heart failure and respiratory distress. Juvenile and adult forms are due to partial enzyme deficiency. Symptoms appear later and the disease has a chronic progressive course (Lewandowska, 2008). Adult -onset type of Pompe disease is associated with progressive respiratory failure resulting from progressive respiratory muscle weakness (WierzbaBobrowicz, 2007). Patients with adult-onset type of Pompe disease often have sleepdisordered breathing (Bembi, 2008; Mellies, 2001). These problems usually occur before the total respiratory failure. Sleep-disordered breathing is usually present in the REM sleep phase in forms of central apneas or hypopneas (Mellies, 2001). Since Pompe is a rare disease, few studies have been published regarding the prevalence of SDB in this disease. In one study performed in 27 patients with juvenile and adult form, sleep-disordered breathing was found in 13 patients, 12 of which had diaphragm weakness (Mellies, 2001). Respiratory disorders: hypopneas and apneas, occurred primarily during REM sleep and correlated with 
decreased tidal volumes, as measured by spirometry during the day. In some patient overnight non-invasive mechanical ventilation were initiated (Mellies, 2001). Recommendations of treatment and diagnosis of Pompe disease suggest control polysomnography study and initiation of respiratory treatment as early as possible in patients with significant SDB (Bembi, 2008).

\section{Neurodegenerative diseases of the central nervous system and SDB}

\subsection{Alzheimer disease}

Searching for links between Alzheimer's disease and sleep-disordered breathing has already started in the eighties. Cognitive deficits observed in individuals with SDB was seen as a preliminary stage in the development of dementia. Cognitive deficits in individuals with impaired respiratory function were found on both verbal, spatial and executive functions as well as short-term memory (Naegele, 1995; Alchanatis, 2005). A number of pathomechanisms may contribute to cognitive impairment in patients with respiratory disorders. The important part play episodes of hypoxia and subsequent oxidative stress resulting in impaired cholinergic transmission in the central nervous system (Gibson, 1981; Shimada, 1981). Another pathomechanism may be associated with changes in cerebral blood flow, observed during sleep -significant hypoperfusion after an episode of apnea. Studies using magnetic resonance spectroscopy showed a decrease in metabolism in the frontal lobes in people with severe respiratory problems during sleep (Alchanatis, 2004) and a decrease in metabolism in the white matter (Kamba, 1997). However, biochemical studies, concerning the biochemical markers of neuronal damage (S-100 $\beta$ protein), showed no significant differences between patients with impaired breathing during sleep and the control group (Jordan, 2002). Homocysteine levels did not differ in patients with apneas compared with the control group (Svatikova, 2004). The study of magnetic resonance and computed tomography show damage to white matter in patients with apneas (Kamba, 2001; Macey, 2006) and reduction of the total intracranial brain volume (O'Donoghue, 2005). Another argument in favor of the relationship between dementia and apneas was the discovery of frequent occurrence of apolipoprotein genotype ApoE4 in people with sleep apneas (Kadotani, 2001; Gottlieb, 2004). There were several studies conducted on the effects of sleep apnea treatment on improvement of cognitive functions. In most studies a positive effect of introducing CPAP therapy was found on improvement of cognitive functions (Feuerstein, 1997; Bliwise, 2002; Zimmerman, 2006). It was also observed a beneficial effect of donepezil treatment on reducing the number of apneas during sleep and improvement of sleep architecture (Moraes, 2008). The degree of cognitive impairment observed in patients with sleep-disordered breathing, however, is significantly lower and more slowly progressive than in those with Alzheimer's disease (Bliwise, 2002). Daytime sleepiness, which is a symptom of respiratory distress has a significant impact on cognitive impairment (Feuerstein, 1997). More and more evidence points to a potential relationship between vascular dementia and sleep-disordered breathing. Early studies showed a significantly higher incidence of respiratory distress in patients with vascular dementia (Hoch, 1986; Bliwise, 1989). The authors also showed a correlation between the severity of respiratory disorders and dementia (Reynolds, 1985). These studies, however, were performed on small groups of patients (up to 30 our participants). Newer studies show a similar incidence of sleep-disordered breathing in patients with Alzheimer's disease as in the general population of similar age (Bliwise, 2002). However, vascular dementia associated with lacunar strokes 
and damage to white matter, occurs more frequent in patients with obstructive sleep apneas (Bliwise, 2002; Matthews, 2003).

\subsection{Parkinson's disease}

Parkinson's disease is associated with many sleep disorders which include excessive daytime sleepiness, insomnia, abnormal sleep architecture, restless legs syndrome and sleep disorders associated with REM sleep stage (Dhawan, 2006; Postuma, 2009). It was thought that excessive daytime sleepiness is associated with concomitant breathing disorders during sleep. Most studies did not confirm this hypothesis. Sleep-disordered breathing in patients with Parkinson's disease are at a level similar to the prevalence in the population of people in middle age and older (Diederich, 2005; Jahan, 2009). The degree of severity of Parkinson's disease does not affect the frequency and severity of respiratory distress (Young, 2002). One publication noted a higher incidence of mild obstructive breathing disorders during sleep in patients with Parkinson's disease compared with controls (Maria, 2003). Parkinson's disease patients who present with symptoms of disordered breathing during sleep should be performed diagnostic tests and the treatment should be implemented immediately. It is known that excessive daytime sleepiness, cognitive impairment and depressive reactions, caused by sleep-disordered breathing, may exacerbate the non-motor symptoms of the Parkinson's disease (Monaca, 2006).

\subsection{Multiple system atrophy (MSA)}

In the course of the multiple system atrophy a number of types of SDB may occur (Gilman, 2003). Obstructive (Munschauer, 1990; Glass, 2006) central (Glass, 2006), and mixed disorders of breathing pattern (Guilleminault, 1981) were found. Respiratory disorders and respiratory failure may be the first sign of disease. Glass and colleagues (2006) described 6 cases of MSA beginning with respiratory disturbances. Leading respiratory symptoms were excessive daytime sleepiness, laryngeal stridor during sleep, and dyspnea on exertion. Polysomnographic studies have shown co-existing obstructive disorders associated with laryngeal stridor (caused by paralysis of vocal cords) and the numerous apneas and hypopneas of central type. Patomechanisms which links MSA with respiratory problems, concern both neural control of breathing rhytmogenesis and respiratory airways. It has been shown in postmortem studies reduced excitatory projection from the thalamus (behavioral respiratory rhythm drive) to the dorsal inspiratory neurons (Gilman 2003) and a significant loss of neurons in the brainstem chemoreceptive neurons (metabolic respiratory drive) (Benarroch, 2007). Loss of serotonergic neurons that stimulate the nucleus ambiguous, observed in MSA (Weston, 2004), causes weakening of negative throat pressure reflexes and may be responsible for laryngeal stridor and obstructive sleep apneas (Bennaroch, 2007). The loss of dopaminergic neurons in the periventricular gray matter, probably responsible for the maintenance of wakefulness, can affect both the respiratory rhythmogenesis, as well as excessive daytime sleepiness (Bennaroch, 2009).

\section{SDB in epilepsy}

The increased incidence of seizures during the night has been known for a long time. Mechanisms associated with the generation of epileptic seizures during sleep are not fully understood. It has been suggested there are several mechanisms of pathological 
synchronization of brain bioelectrical activity, triggered by physiological stages of sleep (Gigli, 1992). The phases of sleep in which there is greatest risk of seizures include the phases associated with a higher probability of awakening - mainly phase I and II NREM sleep type. Phase of sleep associated with EEG desynchronization - REM is characterized by a lower risk of seizures. The probability of awakening during sleep increases the risk of seizure in the case of idiopathic generalized epilepsies (Bonakis, 2009). A similar mechanism was proposed in focal and secondarily generalized seizures (Manni, 2005). Also in these types of epilepsy light sleep phase (I and II NREM) may initiate abnormal synchronous epileptic discharges. The EEG patterns associated with arousal (K complexes) trigger pathological EEG hypersynchrony in the second phase of NREM sleep. Seizure during sleep is associated with the interruption of the continuity of sleep and disorder of its architecture. Seizure, both partial (Bateman, 2008) and generalized (Seyal, 2009), can cause apnea of central origin. It is probably due to the short-term disturbances of respiratory rhythmogenesis during sleep by hypersynchronic epileptic discharges. The effects of sleepapnea during seizures, are prolonged hypoxia with a decrease in blood oxygen saturation to $58 \%$ and a significant hypercapnia and acidosis (Seyal, 2009). The mechanism of respiratory arrest, and neurogenic pulmonary edema associated with asystole are some of the hypothetical mechanisms of sudden unexpected death in epilepsy (SUDEP) (Nashef, 2007; So, 2008; Jehi, 2008; Pezzela, 2009). Descriptions of near SUDEP cases during polysomnographic studies indicate sleep apnea as an important part of the clinical picture (So, 2000; Trotti, 2009). The pathogenesis of SUDEP is probably associated with the diving reflex mechanisms, generated during apnea $($ So, 2008) followed by significant bradycardia to asystole and a significant increase in systemic blood pressure, which significantly increases the afterload and metabolic demands of myocardium. In literature there are two cases of patients in whom obstructive sleep apnea caused changes in the EEG and cerebral hypoxia, which in one case ended in death, and in the second with transient encephalopathy (Dyken, 2004). Animal model of SUDEP proves that central apnea and myocardial ischemic changes should be considered as the main patomechanisms of death in the course of a seizure (Johnston, 1997). The relationship between sleep-disordered breathing and epilepsy also revealed a higher incidence of obstructive sleep apneas in patients with epilepsy compared with the general population matched for age. In various studies, the incidence of sleep-disordered breathing is estimated between $5 \%$ and $63 \%$ in patients with epilepsy (Malow, 1997; Malow, 2000; Beran, 1999; Weatherwax, 2003; Malow, 2003, Hollinger, 2006). Higher incidence of obstructive apneas and hypopneas was found in patients with drugresistant epilepsy (Malow, 2000). The co-existence of idiopathic epilepsy and obstructive sleep apneas was also observed in the elderly population (Chihorek, 2007). In the cited paper the authors suggest that the increase in the number of new cases of idiopathic epilepsy in the elderly is associated with an increased incidence of sleep-disordered breathing in these patients. A number of studies indicate the beneficial effect of treatment with CPAP method for reducing the number of seizures (Malow, 2000, Hollinger, 2006; Chihorek, 2007; Malow, 2008). Precise pathomechanisms linking apnea with seizure are unknown. There are several reasons that may come up for coexistence of the observed higher incidence of seizures with sleep-disordered breathing. Particularly interesting is the observation on the significantly higher prevalence of sleep apnea in patients with drugresistant epilepsy (Malow, 2000). One of the pathomechanisms may be related to apnea hypoxia, which leads to decrease of the available pool of ATP in cortical neurons. It was shown that lack of ATP increases the excitability of neurons by the partial depolarization of 
the cell membrane (Somjen, 2001), which reduces the seizure threshold. Reducing the amount of ATP in neurons also causes increase in amplitude of the sodium ion current in neurons (Rola, 2004), which may accelerate neuron depolarization and action potential generation. Another possible pathomechanism, causing seizures during sleep apnea, is the increased number of awakenings and disturbed sleep architecture. Obstructive type of respiratory disorders are most common during light sleep (stage I and II NREM sleep), during the instability of the respiratory center. In these phases, there are also more awakenings. K complexes and sleep spindles which occur in II phase of NREM are associated with increased pathological hyper synchrony (Bonakis, 2009). Patients with sleepdisordered breathing have disturbed sleep architecture. There is an increased time of shallow sleep (stage I and II NREM) and the reduction or total absence of REM sleep stage. As mentioned above, the NREM sleep, I and Phase II contribute to the occurrence of seizures, while desynchronization of bioelectrical activity of the brain in REM stage prevents seizures (Seyal, 2009). A patient with severe sleep apneas and disturbed sleep architecture is staying longer in the NREM stages, exposed to the induction of seizures, and less in the REM stages of sleep associated with lower risk of seizure. Although the consequence of these pathomechanisms may be increased risk of seizures in patients with apneas, but thanks to the possible treatment a reduction in seizure frequency is observed. Case reports noted the reduction of symptoms of sleep-disordered breathing after surgical treatment of epilepsy (Földvary-Schaefer, 2008) and the reverse effect of vagal stimulation (Holmes, 2003) which indicates a mutual relationship of these two disease entities.

\section{References}

[1] Guyton AC, Hall EJ, Textbook of Medical Physiology, W.B. Saunders Company; 11th edition 2005

[2] Przybyłowski T, Bangash MF, Reichmuth K, Morgan BJ, Skatrud JB, Dempsey JA, Mechanisms of the cerebrovascular response to apnoea in humans, J. Physiol., 2003; 548: 323 - 332.

[3] Meadows GE, O'Driscoll DM, Simonds AK, Morrell MJ, Corfield DR, Cerebral blood flow response to isocapnic hypoxia during slow-wave sleep and wakefulness, J Appl Physiol, 2004; 97: 1343 - 1348.

[4] Jennum P, Borgesen SE, Intracranial pressure and obstructive sleep apnea, Chest, 1989; 95: 279 - 283.

[5] Silvestrini M, Rizzato B, Placidi F, Baruffaldi R, Bianconi A, Diomedi M, Carotid Artery Wall Thickness in Patients With Obstructive Sleep Apnea Syndrome, Stroke, 2002; 33: 1782 - 1785.

[6] Nachtmann A, Stang A, Wang YM, Wondzinski E, Thilmann AF, Association of obstructive sleep apnea and stenotic artery disease in ischemic stroke patients, Atherosclerosis, 2003; 169(2): 301-7.

[7] Behrens S, Spengos K, Hennerici M, Acceleration of cerebral blood flow velocity in a patient with sleep apnea and intracranial arterial stenosis, Sleep Breath, 2002; 6(3): 111-4.

[8] Balfors EM, Franklin KA, Impairment of cerebral perfusion during obstructive sleep apneas, Am. J. Respir. Crit. Care Med., 1994; 150: 1587 - 1591.

[9] Urbano F, Roux F, Schindler J, Mohsenin V, Impaired cerebral autoregulation in obstructive sleep apnea, J Appl Physiol, 2008; 105: 1852 - 1857. 
[10] Culebras A, Cerebrovascular disease and sleep, Curr Neurol Neurosci Rep, 2004; 4(2): 164-9.

[11] Netzer N, Werner P, Jochums I, Lehmann M, Strohl KP, Blood Flow of the Middle Cerebral Artery With Sleep-Disordered Breathing: Correlation With Obstructive Hypopneas, Stroke, 1998; 29: 87 - 93.

[12] Mohsenin V, Sleep-disordered breathing: implications in cerebrovascular disease, Prev Cardiol, 2003; 6(3): 149-54

[13] Yaggi H, Mohsenin V, Sleep-disordered breathing and stroke, Clin Chest Med, 2003; 24(2): 223-37.

[14] Partinen M, Palomaki H, Snoring and cerebral infarction, Lancet, 1985; 2(8468): 1325-6.

[15] Palomaki H, Partinen M, Juvela S, Kaste M, Snoring as a risk factor for sleep-related brain infarction, Stroke, 1989; 20: 1311 - 1315.

[16] Palomaki H, Snoring and the risk of ischemic brain infarction, Stroke, 1991; 22: 1021 1025.

[17] Koskenvuo M, Kaprio J, Telakivi T, Partinen M, Heikkilä K, Sarna S, Snoring as a risk factor for ischaemic heart disease and stroke in men, Br Med J (Clin Res Ed), 1987; 294: 16 - 19.

[18] Hu FB, Willett WC, Manson JE, Colditz GA, Rimm EB, Speizer FE, Hennekens CH, Stampfer MJ, Snoring and risk of cardiovascular disease in women, J. Am. Coll. Cardiol., 2000; 35: 308 - 313.

[19] Harbison JA, Gibson GJ, Snoring, sleep apnoea and stroke: chicken or scrambled egg?, QJM, 2000; 93: 647 - 654.

[20] Davies DP, Rodgers H, Walshaw D, James OF, Gibson GJ, Snoring, daytime sleepiness and stroke: a case-control study of first-ever stroke, J Sleep Res, 2003; 12(4): 313-8.

[21] Janszky I, Ljung R, Rohani M, Hallqvist J, Heavy snoring is a risk factor for case fatality and poor short-term prognosis after a first acute myocardial infarction. Sleep, 2008; 31(6): 801-7.

[22] Williams CJ, Hu FB, Patel SR, Mantzoros CS, Sleep Duration and Snoring in Relation to Biomarkers of Cardiovascular Disease Risk Among Women With Type 2 Diabetes, Diabetes Care, 2007; 30: 1233 - 1240.

[23] Al-Delaimy WK, Manson JE, Willett WC, Stampfer MJ, Hu FB, Snoring as a Risk Factor for Type II Diabetes Mellitus: A Prospective Study, Am. J. Epidemiol., 2002; 155: $387-393$.

[24] Lee SA, Amis TC, Byth K, Larcos G, Kairaitis K, Robinson TD, Wheatley JR, Heavy snoring as a cause of carotid artery atherosclerosis. Sleep, 2008; 31(9): 1207-13.

[25] Good DC, Henkle JQ, Gelber D, Welsh J, Verhulst S, Sleep-Disordered Breathing and Poor Functional Outcome After Stroke, Stroke, 1996; 27: 252 - 259.

[26] Mohsenin V, Valor R. Sleep apnea in patients with hemispheric stroke. Arch Phys Med Rehabil, 76: 71-76. 1995

[27] Bassetti C , Aldrich MS, Sleep apnea in acute cerebrovascular diseases: final report on 128 patients. Sleep, 1999; 22(2): 217-23.

[28] Bassetti C, Aldrich MS, Chervin RD, Quint D, Sleep apnea in patients with transient ischemic attack and stroke: A prospective study of 59 patients, Neurology, 1996; 47: $1167-1173$.

[29] Bassetti C, Aldrich MS, Quint D, Sleep-Disordered Breathing in Patients With Acute Supra- and Infratentorial Strokes : A Prospective Study of 39 Patients, Stroke, 1997; 28: 1765 - 1772. 
[30] Parra O, Arboix A, Bechich S, Garcia-Eroles L, Mentserrat JM, Lopez JA, Ballester E, Guerra JM, Sopena JJ, Time Course of Sleep-related Breathing Disorders in FirstEver Stroke or Transient Ischemic Attack, Am. J. Respir. Crit. Care Med., 2000; 161: 375 - 380 .

[31] Wessendorf TE, Wang YM, Thilmann AF, Sorgenfrei U, Konietzko N, Teschler H, Treatment of obstructive sleep apnoea with nasal continuous positive airway pressure in stroke, Eur. Respir. J., 2001; 18: 623 - 629.

[32] Turkington PM, Bamford J, Wanklyn P, Elliott MW, Prevalence and Predictors of Upper Airway Obstruction in the First 24 Hours After Acute Stroke, Stroke, 2002; 33: 2037 $-2042$.

[33] Harbison J, Ford GA, James OFW, Gibson GJ, Sleep-disordered breathing following acute stroke, QJM, 2002; 95: 741 - 747.

[34] Iranzo A, Santamaría J, Berenguer J, Sánchez M, Chamorro A, Prevalence and clinical importance of sleep apnea in the first night after cerebral infarction, Neurology, 2002; 58: 911 - 916.

[35] Kaneko Y, Floras JS, Usui K, Plante J, Tkacova R, Kubo T, Ando SI, Bradley TD, Cardiovascular Effects of Continuous Positive Airway Pressure in Patients with Heart Failure and Obstructive Sleep Apnea, N. Engl. J. Med., 2003; 348: 1233 - 1241.

[36] Kaneko Y, Hajek VE, Zivanovic V, Raboud J, Bradley TD, Relationship of sleep apnea to functional capacity and length of hospitalization following stroke. Sleep, 2003; 26(3): 293-7.

[37] Turkington PM, Allgar V, Bamford J, Wanklyn P, Elliott MW, Effect of upper airway obstruction in acute stroke on functional outcome at 6 months, Thorax, 2004; 59: 367 $-371$.

[38] Martinez-Garcia MA, Galiano Blancart R, Cabero Salt L, Soler Cataluna JJ, Escamilla T, Roman Sanchez P, Prevalence of sleep-disordered breathing in patients with acute ischemic stroke: influence of onset time of stroke, Arch Bronconeumol, 2004; 40(5): 196-202.

[39] Selic C, Siccoli MM, Hermann DM, Bassetti CL, Blood Pressure Evolution After Acute Ischemic Stroke in Patients With and Without Sleep Apnea, Stroke, 2005; 36: 2614 2618.

[40] Dziewas R, Humpert M, Hopmann B, Kloska SP, Ludemann P, Ritter M, Dittrich R, Ringelstein EB, Young P, Nabavi DG, Increased prevalence of sleep apnea in patients with recurring ischemic stroke compared with first stroke victims. J Neurol, 2005; 252(11): 1394-8.

[41] Yaggi HK, Concato J, Kernan WN, Lichtman JH, Brass LM, Mohsenin V, Obstructive Sleep Apnea as a Risk Factor for Stroke and Death, N. Engl. J. Med., 2005; 353: 2034 - 2041.

[42] Arzt M, Young T, Finn L, Skatrud JB, Douglas Bradley T, Association of Sleepdisordered Breathing and the Occurrence of Stroke, Am. J. Respir. Crit. Care Med., 2005; 172: 1447 - 1451.

[43] Nopmaneejumruslers C, Kaneko Y, Hajek V, Zivanovic V, Douglas Bradley T, CheyneStokes Respiration in Stroke: Relationship to Hypocapnia and Occult Cardiac Dysfunction, Am. J. Respir. Crit. Care Med., 2005; 171: 1048 - 1052

[44] Munoz R, Duran-Cantolla J, Martínez-Vila E, Gallego J, Rubio R, Aizpuru F, De La Torre G, Severe Sleep Apnea and Risk of Ischemic Stroke in the Elderly, Stroke, 2006; 37: 2317 - 2321. 
[45] Sahlin C, Sandberg O, Gustafson Z, Bucht G, Carlberg B, Stenlund H, Franklin KA, Obstructive Sleep Apnea Is a Risk Factor for Death in Patients With Stroke: A 10Year Follow-up, Arch Intern Med, 2008; 168: 297 - 301.

[46] Valham F, Mooe T, Rabben T, Stenlund H, Wiklund U, Franklin KA, Increased Risk of Stroke in Patients With Coronary Artery Disease and Sleep Apnea: A 10-Year Follow-Up, Circulation, 2008; 118: 955 - 960.

[47] Cherkassky T. Oksenberg A. Froom P. Ring H., Sleep-related breathing disorders and rehabilitation outcome of stroke patients: a prospective study, American Journal of Physical Medicine \& Rehabilitation. 2003; 82(6):452-5.

[48] Hui DSC, Choy DKL, Lawrence KS, Wong, Fanny WS Ko, Thomas ST Li, Jean Woo, Kay $\mathrm{R}$, Prevalence of sleep-Disordered Breathing and Continuos Positive Airway Pressure Compliance, Chest 2002; 122 (3).

[49] Sandberg O, Franklin KA, Bucht G, Eriksson S, Gustafson Y, Nasal continuous positive airway pressure in stroke patients with sleep apnoea: a randomized treatment study, Eur. Respir. J., 2001; 18: 630 - 634.

[50] Wessendorf TE,. Wang YM, Thilmann AF, Sorgenfrei U, Konietzko N, Teschler H, Treatment of obstructive sleep apnoea with nasal continuous positive airway pressure in stroke, Eur. Respir. J., 2001; 18: 623 - 629.

[51] Martínez-García MA, Galiano-Blancart R, Román-Sánchez P, Soler-Cataluña JJ, CaberoSalt L, Salcedo-Maiques E, Continuous Positive Airway Pressure Treatment in Sleep Apnea Prevents New Vascular Events After Ischemic Stroke, Chest, 2005; 128: 2123 - 2129.

[52] Hsu CY, Vennelle M, Li HY, Engleman HM, Dennis MS, Douglas NJ, Sleep-disordered breathing after stroke: a randomised controlled trial of continuous positive airway pressure, J. Neurol. Neurosurg. Psychiatry, 2006; 77: 1143 - 1149.

[53] Buchner NJ, Sanner BM, Borgel J, Rump LC, Continuous Positive Airway Pressure Treatment of Mild to Moderate Obstructive Sleep Apnea Reduces Cardiovascular Risk, Am. J. Respir. Crit. Care Med., 2007; 176: 1274 - 1280.

[54] Goldstein LB, Adams R, Alberts MJ, Appel LJ, Brass LM, Bushnell CD, Culebras A, DeGraba TJ, Gorelick PB, Guyton JR, Hart RG, Howard G, Kelly-Hayes M, Nixon JVI, Sacco RL, Primary Prevention of Ischemic Stroke: A Guideline From the American Heart Association/American Stroke Association Stroke Council: Cosponsored by the Atherosclerotic Peripheral Vascular Disease Interdisciplinary Working Group; Cardiovascular Nursing Council; Clinical Cardiology Council; Nutrition, Physical Activity, and Metabolism Council; and the Quality of Care and Outcomes Research Interdisciplinary Working Group: The American Academy of Neurology affirms the value of this guideline. Circulation, 2006; 113: e873 - e923.

[55] Martínez-García MA, Soler-Cataluña JJ, Ejarque-Martínez L, Soriano Y, Román-Sánchez P, Illa FB, Montserrat Canal JM, Durán-Cantolla J, Continuous Positive Airway Pressure Treatment Reduces Mortality in Patients with Ischemic Stroke and Obstructive Sleep Apnea: A 5-Year Follow-up Study, Am. J. Respir. Crit. Care Med., 2009; 180: 36 - 41.

[56] Cormican LJ, Higgins S, Davidson AC, Howard R, Williams AJ, Multiple system atrophy presenting as central sleep apnoea, Eur. Respir. J., 2004; 24: 323 - 325.

[57] Auer RN, Rowlands CG, Perry SF, Remmers JE, Multiple sclerosis with medullary plaques and fatal sleep apnea (Ondine's curse). Clin Neuropathol, 1996; 15(2): 101-5. 
[58] Aboussouan LS, Respiratory disorders in neurologic diseases. Cleveland Clinic Journal of Medicine, 2005; 72: 511 - 520.

[59] Katz SL, Assessment of Sleep-Disordered Breathing in Pediatric Neuromuscular Diseases, Pediatrics, 2009; 123: S222 - S225.

[60] Landon C, AMBULATORY PHYSIOLOGIC MONITORING IN HOME ASSESSMENT OF NEUROMUSCULAR DISEASE, Chest Meeting Abstracts, 2006; 130: 238 S - 239 S.

[61] Bach JR, Gonçalves MR, Noninvasive ventilation or paradigm paralysis?, Eur. Respir. J., 2004; 23: 651.

[62] Birnbaum S, Pulse Oximetry: Identifying Its Applications, Coding, and Reimbursement, Chest, 2009; 135: 838 - 841.

[63] Bourke SC, Bullock RE, Williams TL, Shaw PJ, Gibson GJ, Noninvasive ventilation in ALS: Indications and effect on quality of life, Neurology, 2003; 61: 171 - 177.

[64] Bourke SC, Gibson GJ, Sleep and breathing in neuromuscular disease, Eur. Respir. J., 2002; 19: 1194 - 1201.

[65] Bourke SC, Tomlinson M, Williams TL, Bullock RE, Shaw PJ, Gibson GJ, Effects of noninvasive ventilation on survival and quality of life in patients with amyotrophic lateral sclerosis: a randomized controlled trial. Lancet Neurol, 2006; 5(2): 140-7.

[66] Farrero E, Prats E, Povedano M, Martinez-Matos JA, Manresa F, Escarrabill J, Survival in Amyotrophic Lateral Sclerosis With Home Mechanical Ventilation: The Impact of Systematic Respiratory Assessment and Bulbar Involvement, Chest, 2005; 127: 2132 - 2138.

[67] Mustfa N, Walsh E, Bryant V, Lyall RA, Addington-Hall A, Goldstein LH, Donaldson N, Polkey MI, Moxham J, Leigh PN, The effect of noninvasive ventilation on ALS patients and their caregivers, Neurology, 2006; 66: 1211 - 1217.

[68] Ambrosino N, Carpenè N, Gherardi M, Chronic respiratory care for neuromuscular diseases in adults, Eur. Respir. J., 2009; 34: 444 - 451.

[69] Tabachnik E, Muller NL, Bryan AC, Levison H, Changes in ventilation and chest wall mechanics during sleep in normal adolescents,J Appl Physiol, 1981; 51: 557 - 564.

[70] Lyall RA, Donaldson N, Polkey MI, Leigh PN, Moxham J, Respiratory muscle strength and ventilatory failure in amyotrophic lateral sclerosis, Brain, 2001; 124: 2000 - 2013.

[71] Hadjikoutis S, Wiles CM, Venous serum chloride and bicarbonate measurements in the evaluation of respiratory function in motor neuron disease, QJM, 2001; 94 : 491 - 495.

[72] Santos C, Braghiroli A, Mazzini L, Pratesi R, Oliveira LV, Mora G, Sleep-related breathing disorders in amyotrophic lateral sclerosis. Monaldi Arch Chest Dis, 2003; 59(2): 160-5.

[73] Arnulf I, Similowski T, Salachas F, Garma L, Mehiri S, Attali V, Behin-Bellhesen V, meininger V, Derenne JP, Sleep Disorders and Diaphragmatic Function in Patients with Amyotrophic Lateral Sclerosis, Am. J. Respir. Crit. Care Med., 2000; 161: 849 856.

[74] Takekawa H, Kubo J, Miyamoto T, Miyamoto M, Hirata K, Amyotrophic lateral sclerosis associated with insomnia and the aggravation of sleep-disordered breathing. Psychiatry Clin Neurosci, 2001; 55(3): 263-4.

[75] Kimura K, Tachibana N, Kimura J, Shibasaki H, Sleep-disordered breathing at an early stage of amyotrophic lateral sclerosis. J Neurol Sci, 1999; 164(1): 37-43.

[76] Ferguson KA, Ahmad D, George CFP, Strong MJ, Sleep-Disordered Breathing in Amyotrophic Lateral Sclerosis, Chest, 1996; 110: 664 - 669. 
[77] David WS, Bundlie SR, Mahdavi Z, Polysomnographic studies in amyotrophic lateral sclerosis. J Neurol Sci, 1997; 152 Suppl 1: S29-35.

[78] Bourke SC, Gibson GJ, Sleep and breathing in neuromuscular disease, Eur. Respir. J., 2002; 19: 1194 - 1201.

[79] Bourke SC, Tomlinson M, Williams TL, Bullock RE, Shaw PJ, Gibson GJ, Effects of noninvasive ventilation on survival and quality of life in patients with amyotrophic lateral sclerosis: a randomised controlled trial. Lancet Neurol, 2006; 5(2): 140-7.

[80] Ozsancak A, D'Ambrosio C, Hill NS, Nocturnal Noninvasive Ventilation, Chest, 2008; 133: 1275 - 1286.

[81] Barbe F, Quera-Salva MA, McCann C, Gajdos P, Raphael JC, de Lattre J, Agusti AG, Sleep-related respiratory disturbances in patients with Duchenne muscular dystrophy, Eur. Respir. J., 1994; 7: 1403 - 1408.

[82] Smith PE, Edwards RH, Calverley PM , Ventilation and breathing pattern during sleep in Duchenne muscular dystrophy. Chest, 1989; 96: 1346 - 1351.

[83] Suresh S, Wales P, Dakin C, Harris MA, Cooper DG, Sleep-related breathing disorder in Duchenne muscular dystrophy: disease spectrum in the paediatric population. J Paediatr Child Health, 2005; 41(9-10): 500-3.

[84] Kirk VG, Flemons WW, Adams C, Rimmer KP, Montgomery MD, Sleep-disordered breathing in Duchenne muscular dystrophy: a preliminary study of the role of portable monitoring. Pediatr Pulmonol, 2000; 29(2): 135-40.

[85] Della Marca G, Frusciante R, Dittoni S, Vollono C, Buccarella C, Iannaccone E, Rossi M, Scarano E, Pirronti T, Cianfoni A, Mazza S, Tonali PA, Ricci E, Sleep disordered breathing in facioscapulohumeral muscular dystrophy. J Neurol Sci, 2009; 285(1-2): 54-8.

[86] Rowland LP, 11th ed Merritt`s Neurology, 2005, Lippincot, Williams\&Wilkins

[87] Finnimore AJ, Jackson RV, Morton A, Lynch E, Sleep hypoxia in myotonic dystrophy and its correlation with awake respiratory function. Thorax, 1994; 49: 66 - 70.

[88] Kiyan E, Okumus G, Cuhadaroglu C, Deymeer F, Sleep apnea in adult myotonic dystrophy patients who have no excessive daytime sleepiness. Sleep Breath, May 2009.

[89] Labanowski M, Schmidt-Nowara W, Guilleminault C, Sleep and neuromuscular disease: Frequency of sleep-disordered breathing in a neuromuscular disease clinic population, Neurology, 1996; 47: 1173 - 1180.

[90] Laberge L, Bégin P, Dauvilliers Y, Beaudry M, Laforte M, Jean S, Mathieu J, polysomnographic study of daytime sleepiness in myotonic dystrophy type $1, \mathrm{~J}$. Neurol. Neurosurg. Psychiatry, 2009; 80: 642 - 646.

[91] Ono S, Takahashi K, Jinnai K, Kanda F, Fukuoka Y, Kurisaki H, Mitake S, Inagaki T, Yamano T, Nagao K, Loss of serotonin-containing neurons in the raphe of patients with myotonic dystrophy: A quantitative immunohistochemical study and relation to hypersomnia, Neurology, 1998; 50: 535 - 538.

[92] Martinez-Rodriguez JE, Lin L, Iranzo A, Genis D, Marti MJ, Santamaria J, Mignot E, Decreased hypocretin-1 (Orexin-A) levels in the cerebrospinal fluid of patients with myotonic dystrophy and excessive daytime sleepiness. Sleep, 2003; 26(3): 287-90.

[93] Quera-Salva MA, Guilleminault, S, Chevret C, Troche G, Fromageot C, Crowe McCann C, R Stoos, de Lattre J, Raphael JC, Gajdos P, Breathing disorders during sleep in myasthenia gravis, Ann Neurol, 1992; 31(1): 86-92. 
[94] Manni R, Piccolo G, Sartori I, Castelnovo G, Raiola E, Lombardi M, Cerveri I, Fanfulla F, Tartara A, Breathing during sleep in myasthenia gravis. Ital J Neurol Sci, 1995; 16(9): 589-94.

[95] Amino A, Shiozawa Z, Nagasaka T, Shindo K, Ohashi K, Tsunoda S, Shintani S, Sleep apnoea in well-controlled myasthenia gravis and the effect of thymectomy. J Neurol, 1998; 245(2): 77-80.

[96] Nicolle MW, Rask S, Koopman WJ, C.F.P. George, J. Adams, Wiebe S, Sleep apnea in patients with myasthenia gravis, Neurology, 2006; 67: 140 - 142

[97] Prudlo J, Koenig J, Ermert S, Juhasz J, Sleep disordered breathing in medically stable patients with myasthenia gravis. Eur J Neurol, 2007; 14(3): 321-6.

[98] Wierzba-Bobrowicz T, Lewandowska E, Lugowska A, Rola R, Stepien T, Ryglewicz D, Pasennik E, Adult glycogenosis type II (Pompe's disease): morphological abnormalities in muscle and skin biopsies compared with acid alpha-glucosidase activity. Folia Neuropathol, 2007; 45(4): 179-86.

[99] Lewandowska E, Wierzba-Bobrowicz T, Rola R, Modzelewska J, Stepien T, Lugowska A, Pasennik E, Ryglewicz D, Pathology of skeletal muscle cells in adult-onset glycogenosis type II (Pompe disease): ultrastructural study. Folia Neuropathol, 2008; 46(2): 123-33.

[100] Bembi B, Cerini E, Danesino C, Donati MA, Gasperini S, Morandi L, Musumeci O, Parenti G, Ravaglia S, Seidita F, Toscano A, Vianello A, Management and treatment of glycogenosis type II, Neurology, 2008; 71: S12 - S36.

[101] Mellies U, Ragette R, C. Schwake, M. Baethmann, T. Voit, and H. Teschler Sleepdisordered breathing and respiratory failure in acid maltase deficiency, Neurology, 2001; 57: 1290 - 1295

[102] Naegele B, Thouvard V, Pepin JL, Levy P, Bonnet C, Perret JE, Pellat J, Feuerstein C, Deficits of cognitive executive functions in patients with sleep apnea syndrome. Sleep, 1995; 18(1): 43-52.

[103] Alchanatis M, N Zias, N Deligiorgis, A Amfilochiou, G Dionellis, and D Orphanidou Sleep apnea-related cognitive deficits and intelligence: an implication of cognitive reserve theory. J Sleep Res, 2005; 14(1): 69-75.

[104] Alchanatis M, Deligiorgis N, Zias N, Amfilochiou A, Gotsis E, Karakatsani A, Papadimitriou A, Frontal brain lobe impairment in obstructive sleep apnoea: a proton MR spectroscopy study, Eur. Respir. J., 2004; 24: 980 - 986.

[105] Gibson GE, Peterson C, Jenden DJ, Brain acetylcholine synthesis declines with senescence, Science, 1981; 213: 674 - 676.

[106] Shimada M, Alteration of acetylcholine synthesis in mouse brain cortex in mild hypoxic hypoxia. J Neural Transm, 1981; 50(2-4): 233-45.

[107] Kamba M, Suto Y, Ohta Y, Inoue Y, Matsuda E, Cerebral Metabolism in Sleep Apnea . Evaluation by Magnetic Resonance Spectroscopy, Am. J. Respir. Crit. Care Med., 1997; 156: 296 - 298.

[108] Jordan W, Hagedohm J, Wiltfang J, Laier-Groeneveld G, Tumani H, Rodenbeck A, Rüther E, Hajak G, Biochemical markers of cerebrovascular injury in sleep apnoea syndrome, Eur. Respir. J., 2002; 20: 158 - 164.

[109] Svatikova A, Wolk R, Magera MJ, Shamsuzzaman AS, Phillips BG, Somers VK, Plasma homocysteine in obstructive sleep apnoea, Eur. Heart J., 2004; 25: 1325 - 1329.

[110] Kamba M, Inoue Y, Higami S, Suto Y, Ogawa T, Chen W, Cerebral metabolic impairment in patients with obstructive sleep apnoea: an independent association 
of obstructive sleep apnoea with white matter change, J. Neurol. Neurosurg. Psychiatry, 2001; 71: 334 - 339.

[111] Macey KE, Macey PM, Woo MA, Henderson LA, Frysinger RC, Harper RK, Alger JR, Yan-Go F, and RM Harper, Inspiratory loading elicits aberrant fMRI signal changes in obstructive sleep apnea. Respir Physiol Neurobiol, 2006; 151(1): 44-60.

[112] O'Donoghue FJ, Briellmann RS, Rochford PD, Abbott DF, Pell GS, Chan CHP, Natalie Tarquinio, Graeme D. Jackson, and Robert J. Pierce Cerebral Structural Changes in Severe Obstructive Sleep Apnea, Am. J. Respir. Crit. Care Med., 2005; 171: 1185 - 1190.

[113] Kadotani H, Kadotani T, Young T, Peppard PE, Finn L, Colrain IM, Murphy GM Jr, Mignot E, Association Between Apolipoprotein E €4 and Sleep-Disordered Breathing in Adults, JAMA, 2001; 285: 2888 - 2890.

[114] Gottlieb DJ, DeStefano AL, Foley DJ, Mignot E, Redline S, Givelber RJ, Young T, APOE $€ 4$ is associated with obstructive sleep apnea/hypopnea: The Sleep Heart Health Study, Neurology, 2004; 63: 664 - 668.

[115] Feuerstein C, Naegele B, Pepin JL, Levy P, Frontal lobe-related cognitive functions in patients with sleep apnea syndrome before and after treatment. Acta Neurol Belg, 1997; 97(2): 96-107.

[116] Bliwise DL, Sleep apnea, APOE4 and Alzheimer's disease 20 years and counting?, J Psychosom Res, 2002; 53(1): 539-46.

[117] Zimmerman ME, Todd Arnedt J, Stanchina M, Millman RP, Aloia MS, Normalization of Memory Performance and Positive Airway Pressure Adherence in MemoryImpaired Patients With Obstructive Sleep Apnea, Chest, 2006; 130: 1772 - 1778.

[118] Moraes W, Poyares D, Sukys-Claudino L, Guilleminault C, Tufik S, Donepezil Improves Obstructive Sleep Apnea in Alzheimer Disease: A Double-Blind, PlaceboControlled Study, Chest, 2008; 133: 677 - 683.

[119] Bliwise DL, Yesavage JA, Tinklenberg JR, Dement WC, Sleep apnea in Alzheimer's disease. Neurobiol Aging, 1989; 10(4): 343-6.

[120] Hoch CC, Reynolds CF 3rd, Kupfer DJ, Houck PR, Berman SR, JA Stack, Sleepdisordered breathing in normal and pathologic aging. J Clin Psychiatry, 1986; 47(10): 499-503.

[121] Reynolds CF 3rd, Kupfer DJ, Taska LS, Hoch CC, Sewitch DE, Restifo K, Spiker DG, Zimmer B, Marin RS, Nelson J, Sleep apnea in Alzheimer's dementia: correlation with mental deterioration. J Clin Psychiatry, 1985; 46(7): 257-61.

[122] Matthews KD, Richter RW, Binswanger's disease: its association with hypertension and obstructive sleep apnea. J Okla State Med Assoc, 2003; 96(6): 265-8; quiz 269-70.

[123] Dhawan V, Healy DG, Pal S, Ray Chaudhuri R, Sleep-related problems of Parkinson's disease, Age Ageing, 2006; 35: 220 - 228.

[124] Postuma RB, Gagnon JF, Vendette M, JY Montplaisir Idiopathic REM sleep behavior disorder in the transition to degenerative disease. Mov Disord, 2009; 24(15): 2225-32.

[125] Diederich NJ, Vaillant M, Leischen M, Mancuso G, Golinval S, Nati R, Schlesser M, Sleep apnea syndrome in Parkinson's disease. A case-control study in 49 patients. Mov Disord, 2005; 20(11): 1413-8.

[126] Jahan I, Hauser RA, Sullivan KL, Miller A, Zesiewicz TA, Sleep disorders in Parkinson's disease., Neuropsychiatr Dis Treat, 2009; 5: 535-40.

[127] Young A, Home M, Churchward T, Freezer N, Holmes P, Ho M, Comparison of sleep disturbance in mild versus severe Parkinson's disease.Sleep, 2002; 25(5): 573-7. 
[128] Maria B, Sophia S, Michalis M, Charalampos L, Andreas P, John ME, Nikolaos SM Sleep breathing disorders in patients with idiopathic Parkinson's disease. Respir Med, 2003; 97(10): 1151-7.

[129] Monaca C, Duhamel A, Jacquesson JM, Ozsancak C, Destee A, Guieu JD, Defebvre L, Derambure P, Vigilance troubles in Parkinson's disease: a subjective and objective polysomnographic study. Sleep Med, 2006; 7(5): 448-53.

[130] Gilman S, Chervin RD, Koeppe RA, Consens FB, Little R, An H, Junck L, Heumann M, Obstructive sleep apnea is related to a thalamic cholinergic deficit in MSA, Neurology, 2003; 61: 35 - 39.

[131] Munschauer FE, Loh L, Bannister R, Newsom-Davis J, Abnormal respiration and sudden death during sleep in multiple system atrophy with autonomie failure, Neurology, 1990; 40: 677.

[132] Glass GA, Josephs KA, Ahlskog JE, Respiratory Insufficiency as the Primary Presenting Symptom of Multiple-System Atrophy, Arch Neurol, 2006; 63: 978 - 981.

[133] Gilman S, Chervin RD, Koeppe RA, Consens FB, Little R, An H, Junck L, Heumann M, Obstructive sleep apnea is related to a thalamic cholinergic deficit in MSA, Neurology, 2003; 61: 35 - 39.

[134] Benarroch EE, Schmeichel AM, Low PA, Parisi JE, Depletion of putative chemosensitive respiratory neurons in the ventral medullary surface in multiple system atrophy, Brain, 2007; 130: 469 - 475.

[135] Benarroch EE, Schmeichel AM, Dugger BN, Sandroni P, Parisi JE, Low PA, Dopamine cell loss in the periaqueductal gray in multiple system atrophy and Lewy body dementia,Neurology, 2009; 73: 106 - 112.

[136] Guilleminault C, Briskin JG, Greenfield MS, Silvestri R, The impact of autonomic nervous system dysfunction on breathing during sleep. Sleep, Sep 1981; 4(3): 263-78.

[137] Weston MC, Stornetta RL, Guyenet PG, Glutamatergic neuronal projections from the marginal layer of the rostral ventral medulla to the respiratory centers in rats. J Comp Neurol, 2004; 473(1): 73-85.

[138] Gigli GL, Calia E, Marciani MG, Mazza S, Mennuni G, Diomedi M, Terzano MG, Janz $D$, Sleep microstructure and EEG epileptiform activity in patients with juvenile myoclonic epilepsy. Epilepsia, 1992; 33(5): 799-804.

[139] Bonakis A, Koutroumanidis M, Epileptic discharges and phasic sleep phenomena in patients with juvenile myoclonic epilepsy, Epilepsia, 2009; 50(11): 2434-45.

[140] Manni R, Terzaghi M, REM behavior disorder associated with epileptic seizures, Neurology, 2005; 64: 883 - 884.

[141] Bateman LM, Li CS, Seyal M, Ictal hypoxemia in localization-related epilepsy: analysis of incidence, severity and risk factors, Brain, 2008; 131: 3239 - 3245.

[142] Seyal M, Bateman M, Ictal apnea linked to contralateral spread of temporal lobe seizures: Intracranial EEG recordings in refractory temporal lobe epilepsy. Epilepsia, 2009.

[143] Nashef L, Hindocha N, Makoff A, Risk factors in sudden death in epilepsy (SUDEP): the quest for mechanisms. Epilepsia, 2007; 48(5): 859-71.

[144] So E, What is known about the mechanisms underlying SUDEP?, Epilepsia, 2008; 49 Suppl 9: 93-8.

[145] Jehi L, Najm IM, Sudden unexpected death in epilepsy: impact, mechanisms, and prevention. Cleveland Clinic Journal of Medicine, 2008; 75: S66. 
[146] Pezzella M, Striano P, Ciampa C, Errichiello L, Penza P, Striano S, Severe pulmonary congestion in a near miss at the first seizure: further evidence for respiratory dysfunction in sudden unexpected death in epilepsy. Epilepsy Behav, 2009; 14(4): 701-2.

[147] So E, Sam MC, Lagerlund TL, Postictal central apnea as a cause of SUDEP: evidence from near-SUDEP incident. Epilepsia, 2000; 41(11): 1494-7.

[148] Trotti LM, Bliwise DL, Sleep apnea as a transient, post-ictal event: report of a case, Epilepsy Res, 2009; 85(2-3): 325-8.

[149] Dyken ME, Yamada T, Glenn CL, Berger HA, Obstructive sleep apnea associated with cerebral hypoxemia and death, Neurology, 2004; 62: 491 - 493.

[150] Johnston SC, Siedenberg R, Min JK, Jerome EH, Laxer KD, Central apnea and acute cardiac ischemia in a sheep model of epileptic sudden death. Ann Neurol, 1997; 42(4): 588-94.

[151] Malow BA, Gail A. Fromes, and Michael S. Aldrich Usefulness of polysomnography in epilepsy patients, Neurology, 1997; 48: 1389 - 1394.

[152] Malow BA, Levy K, Maturen K, Bowes R, Obstructive sleep apnea is common in medically refractory epilepsy patients, Neurology, 2000; 55: 1002 - 1007.

[153] Malow BA, Weatherwax KJ, Chervin RD, Hoban TF, Marzec ML, Martin C, Binns LA; Identification and treatment of obstructive sleep apnea in adults and children with epilepsy: a prospective pilot study.Sleep Med, 2003; 4(6): 509-15.

[154] Beran RG, Plunkett MJ, Holland GJ, Interface of epilepsy and sleep disorders.Seizure, 1999; 8(2): 97-102.

[155] Weatherwax KJ, Lin X, Marzec ML, Malow BA, Obstructive sleep apnea in epilepsy patients: the Sleep Apnea scale of the Sleep Disorders Questionnaire (SA-SDQ) is a useful screening instrument for obstructive sleep apnea in a disease-specific population. Sleep Med, 2003; 4(6): 517-21.

[156] Hollinger P, Khatami R, Gugger M, Hess CW, Bassetti CL, Epilepsy and obstructive sleep apnea. Eur Neurol, 2006; 55(2): 74-9.

[157] Chihorek AM, Abou-Khalil B, and Beth A. Malow Obstructive sleep apnea is associated with seizure occurrence in older adults with epilepsy, Neurology, 2007; 69: 1823 - 1827.

[158] Hollinger P, Khatami R, Gugger M, Hess CW, Bassetti CL, Epilepsy and obstructive sleep apnea. Eur Neurol, 2006; 55(2): 74-9.

[159] Malow BA, Foldvary-Schaefer N, Vaughn BV, Selwa LM, Chervin RD, Weatherwax KJ, Wang L, and Y. Song Treating obstructive sleep apnea in adults with epilepsy: A randomized pilot trial, Neurology, 2008; 71: 572 - 577.

[160] Somjen GG, Mechanisms of Spreading Depression and Hypoxic Spreading Depression-Like Depolarization, Physiol Rev, 2001; 81: 1065 - 1096

[161] Rola R, Szulczyk P, Kinetic properties of voltage-gated Na+ currents in rat muscular sympathetic neurons with and without adenosine triphosphate and guanosine triphosphate in intracellular solution. Neurosci Lett, 2004; 359(1-2): 53-6.

[162] Földvary-Schaefer N, Stephenson L, Bingaman W, Resolution of obstructive sleep apnea with epilepsy surgery? Expanding the relationship between sleep and epilepsy. Epilepsia, 2008; 49(8): 1457-9.

[163] Holmes MD, Chang M, Kapur V, Sleep apnea and excessive daytime somnolence induced by vagal nerve stimulation, Neurology, 2003; 61: 1126 - 1129. 


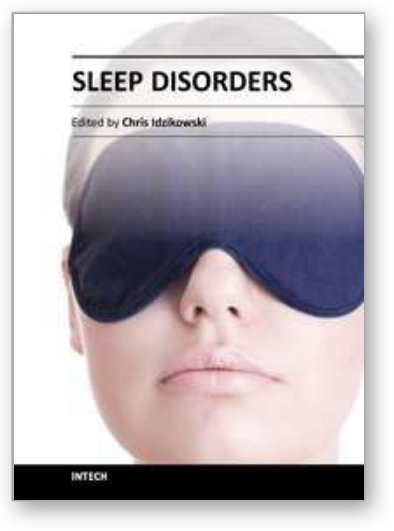

\author{
Sleep Disorders \\ Edited by Dr. Chris Idzikowski
}

ISBN 978-953-51-0293-9

Hard cover, 190 pages

Publisher InTech

Published online 14, March, 2012

Published in print edition March, 2012

For progress to be maintained in a clinical field like sleep medicine, unimpeded, unrestricted access to data and the advances in clinical practice should be available. The reason why this book is exciting is that it breaks down the barriers to dissemination of information, providing scientists, physicians, researchers and interested individuals with a valuable insight into the latest diverse developments within the study of sleep disorders. This book is a collection of chapters, which can be viewed as independent units dealing with different aspects and issues connected to sleep disorders, having in common that they reflect leading edge ideas, reflections and observations. The authors take into account the medical and social aspects of sleep-related disorders, concentrating on different focus groups, from adults to pregnant women, adolescents, children and professional workers.

\title{
How to reference
}

In order to correctly reference this scholarly work, feel free to copy and paste the following:

Rafał Rola (2012). Sleep-Disordered Breathing in Neurological Diseases, Sleep Disorders, Dr. Chris Idzikowski (Ed.), ISBN: 978-953-51-0293-9, InTech, Available from: http://www.intechopen.com/books/sleepdisorders/sleep-apnea-in-stroke

\section{INTECH}

open science | open minds

\section{InTech Europe}

University Campus STeP Ri

Slavka Krautzeka 83/A

51000 Rijeka, Croatia

Phone: +385 (51) 770447

Fax: +385 (51) 686166

www.intechopen.com

\section{InTech China}

Unit 405, Office Block, Hotel Equatorial Shanghai

No.65, Yan An Road (West), Shanghai, 200040, China

中国上海市延安西路65号上海国际贵都大饭店办公楼405单元

Phone: +86-21-62489820

Fax: +86-21-62489821 
(C) 2012 The Author(s). Licensee IntechOpen. This is an open access article distributed under the terms of the Creative Commons Attribution 3.0 License, which permits unrestricted use, distribution, and reproduction in any medium, provided the original work is properly cited. 